be considerably delayed. Thus, a normal chloride level is not incompatible with the diagnosis of tuberculous meningitis, for the level may become appreciably reduced only at an advanced stage in the disease process.

Table 2 summarizes the important changes in the cerebro-spinal fluid. It will be seen that variations between the cellular and chemical responses are of great value in diagnosis, though for ultimate identification additional investigations usually prove necessary. The differences in cellular and chemical responses also serve to emphasize the classification of the causes of meningeal irritation prerinusly advanced on an aetiological basis.

\section{Differentiation of Purulent Meningitides}

The optimal treatment of purulent meningitis depends on precise identification of the causal organism. The species and type can be determined only by accurate bacteriological and, where necessary, immunological methods. In the large majority of cases an immediate result can be $\frac{3}{\infty}$ obtained by staining, either of a direct smear or of $\stackrel{\Phi}{\varrho}$ one made after rapid centrifuging of the cerebro- $c$ spinal fluid. With skilled technique and ex- $\overrightarrow{\vec{D}}$ perience the culture of organisms from the fluid in purulent meningitis is more frequently confirmatory than diagnostic. The severity of the infection can rapidly be gauged by a simple quantitative test for glucose concentration.

The identification of haemophilus influenzae by के the above methods is less frequently successful, $\vec{\circ}$ since its morphological features are unpredictably variable. In difficult cases the capsular swelling phenomenon may be employed.

\section{BIBLIOGRAPHY}

COHEN, H. (1927), Brain, L., 601.

FREMONT-SMITH, F., DAILEY, M. E., and THOMAS, G. W. (1928-29), 7. Clin. Invest., 6, 9.

M. R. C. (1948), Streptomycin in Tuberculosis Trials Committee, Lancet, April 17.

\title{
INFANTILE DIARRHOEA AND VOMITING
}

\author{
By IAN M. Anderson, M.D. (Glasgow), M.R.C.P. (London) \\ Assistant Paediatrician, Westminster Hospital
}

Infantile diarrhoea is a disease of infancy characterized by vomiting, frequent watery motions, rapid dehydration, loss of weight and a high mortality rate.

Diarrhoea and vomiting has always been a major problem to those physicians who have had to deal with diseases of children. Epidemics have been reported since early times. In England as long ago as the mid $\mathrm{I} 7^{\text {th }}$ ceritury epidemics of such magnitude occurred as to lead to the death of 2,000 babies during the hot summer weather of I669-7I (Garrison). ${ }^{1}$ Carter ${ }^{2}$ in 1893 drew attention to the infective nature of the disease and noted its relationship to impure milk; he suggested the use of subcutaneous saline. Wilson ${ }^{3}$ (1927) discussed the bacteriology and pointed out that the disease could be caused by many organisms.

Until the second quarter of the present century infantile diarrhoea and vomiting was synonymous with cholera infantum and the main incidence of the disease was in the summer months. Eventually however, investigations showed that contaminated milk and poor hygienic conditions were the most important factors contributing to the seasonal incidence. With improvement in the milk supply, including the use of pasteurized and dried milks and improvement in sanitation associated with the disappearance of the horse, the extermination of flies and the establishment of Welfare Centres where infant hygiene could be taught to the mothers, there was no longer the same seasonal incidence nor mortality. It is probable that a certain amount of infantile diarrhoea and vomiting has always occurred throughout the year and that when the incidence of summer diarrhoea fell below the level of the all-season diarrhoea between rgro and $\mathrm{I} 930$ this latter attracted attention. Marriott ${ }^{4}$ considered that otitis media and mastoiditis commonly caused infantile diarrhoea and vomiting and following on his papers several others apdeared claiming success in treatment by mastoidectomy. Findlay ${ }^{5}$ (1932) discussed the relationship of otitis media to infantile diarrhoea and vomiting and mentioned the social and seasonal incidence. Craig ${ }^{6}$ (1935) drew attention to the disease as it occurred in the newborn and apart from summer diarrhoea and Dick, ${ }^{7}$ Barenberg ${ }^{8}$ and 
Frant ${ }^{9}$ also drew attention to the disease in the newborn with its highly infectious nature. Frant considered the disease in the newborn as a specific illness and gave as his criteria for diagnosis apparent limitation to babies in the first month of. life, apparent absence of parenteral disease and non-identification with any known organisms.

In most countries cases have been encountered in maternity hospitals, at home and in children's hospitals at varying times in the first year of life. It is generally felt that the disease may occur up till the end of the first year, but that it is preponderantly an illness of early infancy and that 60 to 80 per cent. of cases occur before nine months of age.

\section{Classification}

Amongst numerous classifications, that of Campbell and Cunningham seems adequate. They divide the causative factors into :-

\section{Specific. Infective.}

2. Symptomatic of general diseases or due to local infection.

\section{Dietetic.}

4. Alimentary-infectious complex. (a) Associated with parenteral infection; (b) without evidence of parenteral infection.

These various groups will be discussed in detail. I. Specific. Infective.

(a) Known pathogenic bacteria. Many organisms come into this category including the Dysentery Group of Sonne, Flexner and Shiga, the Salmonella Group, B. Pyocyaneus, etc. In the Dysentery Group the last outbreak reported in infants was that by Watt ${ }^{10}$ (1945) who described an epidemic due to Shiga. McKinlay'11 (1937) reported an outbreak due to Salmonella in which a nurse was the possible carrier. Watt (I945) described an epidemic due to $\mathrm{S}$. Typhimurium, and Seligmann ${ }^{12}$ (1947) reported a similar epidemic. Ensign and Hunter ${ }^{13}$ (1946) reported an epidemic due to P. aeroginosa (B. Pyocyaneus). Felsen ${ }^{14}$ (1942) and Brown ${ }^{15}$ (1946) reported epidemics due to Staphylococcus Aureus.

(b) Bacteria whose aetiological relationship is suspect but not known. (i) Coliform Group.Crowley, Downie, Fulton and Wilson ${ }^{16}$ (I94I) from their investigations in association with three epidemics of diarrhoea in the newborn found that the proportion of coliform organisms in the stools was increased in those infants suffering from the disease and that they were found in much the same proportions in the faeces of healthy contact infants in the same outbreaks, while they were present in much smaller numbers in the faeces of healthy, non-contact infants in normal maternity homes. They came to the conclusion that it was impossible to say whether they were the primary cause of the disease or whether their increase was secondary to a disturbance of the bowel caused by some other agent. Payling Wright ${ }^{17}$ (1948) suggested that through the cessation of breast feeding and the resulting disappearance of aciduric flora from the intestines, the infant may become unduly vulnerable to infection with any of the more pathogenic strains of coliform organisms that may happen to be prevalent in the locality at the time.

(ii) Paracolon Group.- Neter and Clark ${ }^{18}$ summarize the knowledge of the pathogenicity of the paracolon group and consider that :-

I. Organisms may be merely saprophytes.

2. May occur as harmless organisms in diarrhoeal disease caused by enteric pathogens or other incitants.

3. They may be a primary cause of diarrhoeal disease in susreptible individuals.

They stated that there was fairly conclusive evidence that these organisms may cause gastroenteritis (lab. infection) but they felt that further studies were necessary before it was possible to establish or disprove the etiological significance of paracolon organisms in enteral disease. $\mathrm{McClure}^{\mathbf{1}}$ and Baker ${ }^{20}$ describe epidemics where $P$. Fscherichia was found in a high proportion of cases.

(iii) B. Proteus.-Both P. Morgagni and P. Vulgaris have been incriminated as being the causative agents in infective diarrhoea. James ${ }^{21}$ (1947) described an epidemic due to P. Vulgaris. This work awaits confirmation in view of the tendency for these organisms to follow in the wake of a previous specific infection.

\section{Symptomatic of general diseases}

Acute illnesses such as acute pyelitis, meningitis and pneumonia may present with diarrhoeal symptoms and in the same way it may be the main evidence of chronic infections of a similar nature.

\section{Dietetic}

The symptoms are usually more chronic in nature and the motions are usually pale or frothy.

\section{Alimentary infectious complex}

(a) Associated with parenteral infection.-Findlay (1932) disagreed with the American and French workers who stressed the relationship between otitis media and gastro-enteritis and stated that in his opinion the ear was not commonly a causative factor. He quoted Finkelstein as being emphatic that otitis media was not the cause of gastroenteritis. Since then various authors in this country have expressed their views as to the causal relationship. Cooper ${ }^{22}$ (1937) found 40 per cent of cases with parenteral infection, Smellie ${ }^{23}$ 
(1939) 30 per cent., Campbell ${ }^{24}$ (I94I) I3 per cent., Alexander and $\operatorname{Eiser}^{25}$ (1944) 88.6 per cent., Gairdner $^{26}$ (1945) 34 per cent. It is of interest that, as the ears have been incriminated more than any other focus, Patterson and Smith ${ }^{27}$ (1944) reported a study of 120 necropsies in infants and children and found pus in the mastoid cavities in $7 \mathrm{I}$ per cent. and that although the highest incidence was in patients with gastroenteritis it was found almost as often in a wide variety of conditions. Culture of the pus revealed various organisms including Pneumococci, Strep. haemolyticus, Strep. viridans, Staph. pyogenes, B. Coli, etc.

The subject of the relationship between infantile diarrhoea and vomiting and otitis media and mastoiditis is a vexed one and it is further complicated by the fact that there is considerable disagreement amongst paediatricians as to what is meant by an infected ear. Few paediatricians have not had the experience of asking the E.N.T. specialist to operate on what they thought was an infected ear and finding no infection present. Furthermore, as commented upon by Wyllie, ${ }^{28}$ the middle ear at post mortem usually contains some inspissated matter. From my own experience I feel that while otitis media and mastoiditis may undoubtedly cause infantile diarrhoea and vomiting, the number of cases in which this occurs is not over 20 per cent., and probably lower.

(b) Without evidence of parenteral infection.Barenberg, Levy and Grand (1936) suggested that the disease might possibly be caused by a virus and since then various papers have been written suggesting the possibility, and more recently in America attempting to prove this aetiology.

Lyon and Folsom ${ }^{29}$ (194I) described three epidemics occurring at the same time as an influenzal epidemic was present in the community, and they claimed that convalescent serum from influenza patients had a preventative effect. Light and Hodes ${ }^{30}$ (I.943) in each of four separate epidemics isolated a filtrable agent which, when given nasally to young calves, produced a bloody diarrhoea in two to five days which lasted up to three weeks. With each of the four strains successive calf passages were made and after recovery immunity was conferred. Furthermore the serum from six infants after convalescence from the disease conferred complete or partial protection against nasal injection. The material had either to be boiled for ten minutes, or to be exposed to a temperature of $80^{\circ} \mathrm{C}$. for an hour, to be inactivated. Cummings ${ }^{31}$ (1947) claims to have discovered a similar virus but he could not maintain its potency beyond the fifth calf transfer. Sevitt ${ }^{32}$ (1948) criticizes the work of Light and Hodes be- cause the agent withstood boiling and because Deeney in Dublin could not obtain similar results with similar experiments.

Buddingh and $\operatorname{Dodd}^{33}$ in an epidemic of diarrhoea and stomatitis obtained positive reactions in rabbits' cornea but Cummings, in an attempt to repeat their work, found it possible to produce similar lesions to those described by Buddingh and Dodd by traumatizing cornea, traumatizing and applying alundum, and by applying extracts of stools and mouth washings of normal infants and various bacteria, and he concluded that the scarification test was not specific.

\section{Pathology}

One of the striking features of the disease, except in those cases where there is an accompanying acute infection such as otitis media, pyelitis, etc., is the wide discrepancy between the severity of the illness and the findings at autopsy. There may be some congestion of the surface vessels of the gut with marked distension of the large and small intestines. The mesenteric lymph nodes are sometimes moderately enlarged. In the more chronic cases the liver may show fatty infiltration, fibrosis and necrosis and the kidneys, spleen and heart may show parenchymatous dee generation. In cases of long standing, evidence of secondary infection may be found, such as otitis media, bronchopneumonia, mastoiditis, craniaf sinus thrombosis, etc.

\section{Epidemiology}

The epidemiology of the disease is still indeterminate but the American workers Buddingh and Dodd have shown that a causative agent could be isolated from the mouths of doctors and nurses and that it could be transmitted from infant to infant by these carriers.

That the disease is highly infectious is obvious to anyone who has dealt with an epidemic of the disease. It may spread rapidly from infant to infant when it occurs in a hospital ward. Payling Wright, in examining the records of deaths from gastro-enteritis in the Borough of Willesden, found that deaths occurred with unexpected frequency in nearby houses or in short streets. He found evidence of epidemic association and concluded that there was some common local factor, most likely some specific infective agent, responsible for the focal outbreaks in the borough.

\section{Social Incidence}

Apart from epidemics in the newborn the disease is preponderantly one which occurs in the lower strata of society where overcrowding and poor hygiene are liable to occur. 


\section{Seasonal Incidence}

Cooper (1937) found 52.3 per cent. of cases from June-October. Smellie (1939) found a slightly higher incidence from June-October. Campbell (r94I) found 53 per cent. from JuneOctober. Payling Wright (1945) found a slight preponderance in the winter. There is thus, as mentioned previously, a change in the incidence of the disease from a previous summer pre-. ponderance to an overall distribution throughout the year.

\section{Symptomatology}

Incubation period.-This is usually from one to eight days though occasionally much longer periods have been recorded.

Stage of invasion.-There is loss of appetite, disinclination to take feeds, drowsiness, sudden loss of weight, occasional vomiting, increase in the number of stools.

Toxic stage.-The infant changes rapidly from being reasonably healthy to acutely ill and suffering from varying degrees of dehydration and collapse. The stools become projectile, frequent, and vary in colour from yellow to greenish or orange. If unchecked the disease progresses until there is gross dehydration, acidosis, and the Hippocratic facies. The tissues lose their elasticity, the fontanelle and eyes become sunken, and coma gradually develops. Recovery is evidenced by an improvement in the tissue turgor, in the mental state, recovery of appetite and a decrease in the vomiting and in the number of stools.

\section{Diagnosis}

In the presence of an epidemic the diagnosis is relatively simple such as in the epidemics described by Ormiston. In the more sporadic cases, and in slightly older infants, the acute onset and the typical projectile stools with acidosis and rapid loss of weight suggest the condition.

\section{Prognosis}

There is no doubt that, with improvements in nursing care, prevention of cross infection, improved methods of treatment, and the use of modern drugs to tackle secondary infection when it occurs, the mortality from the disease is gradually falling. If, however, one compares the mortality rate of various British authors there is considerable discrepancy. For example Alexander and Eiser (1944) in reviewing a series of 140 cases reported a mortality of 5.7 per cent., but as they found that 88.6 per cent. of their cases had evidence of parenteral infection it is doubtful whether the majority of their cases came under the category of true infectious diarrhoea. Gairdner ( 1945 ) in a series of 216 cases had a mortality rate of 5 I per cent. but the series was adversely affected by the fact that there were 71 cases with a 67 per cent. mortality rate in the first month of life when it is generally recognized that the mortality is highest. Apart from Gairdner's series the mortality rate has been improving. Cooper (r937) 47 per cent., Smellie (1939) 48 per cent., Campbell (1941) 27.7 per cent., Alexander and Eiser (1944) 5.7 per cent.

\section{Prophylaxis}

Breast feeding.- It is well known that breast-fed infants are much less liable to contract the disease. and that the illness is less severe if contracted. This fact has been stressed by Findlay, Cooper, Smellie and Campbell.

\section{Preventive Measures}

There have been a number of epidemics which occurred amongst the newborn and which could have been prevented from spreading if more attention had been paid to the possible means of such a spread. Pollock ${ }^{34}$ (1935) in discussing the overcrowding of nurseries due to lack of space said ' all too frequently nurseries are assigned to what might be designated as left over space and their size is determined by the number of basinettes that can be crowded in without any regard to the spacing or the aisles between them.' Clifford ${ }^{35}$ writes 'outbreaks of epidemics of diarrhoea of the newborn in which no aetiology could be established can be subdivided into two groups. The first consists of outbreaks in nurseries with excellent techniques where careful investigation of the affected patients and of their environment by both bacteriological and epidemiological studies fails to reveal any aetiological agent. In the second, and by far the largest group, investigations failed to reveal any specific organism, but such atrocious nursing and formula-room technique was uncovered that infection with anything was possible.' Without going so far as either of those writers in their assertions a good deal can be done both in the newborn and in the later age groups by more care in the isolation of the patients and proper aseptic precautions on the part of the attendants to prevent the spread of infection once it has occurred. Once a case of diarrhoea has occurred it is essential that the child should be isolated and that if any further cases occur in the ward it should be closed and all fresh admissions should be admitted to a separate ward.

\section{Treatment}

(a) Treat the cause. Where a causal organism can be isolated such as B. Sonne, etc., specific treatment can be undertaken.

(b) Relief of diarrhoea. This is best obtained 
by stopping all fluids by mouth, with perhaps the exception of a few minims of boiled or distilled water to moisten the mouth. This restriction should be maintained until the motions have either ceased or have so much improved in character as to warrant an increase.

(c) Correction of physiological disturbance. Gamble $^{36}$ has shown that one can have a markedly diminished intake from the gastro-intestinal tract which can be covered by a correspondingly diminished output of water and electrolytes by the kidney. When the limit of renal conservation is passed, deficits develop quickly. He has also shown that fluids and electrolytes are not sufficient and that calories must be supplied and by means of a chart what he estimates to be the survival rate in relation to fluid and caloric intake. In a 7 kilo. infant he estimates that the survival period after a severe diarrhoea during which the infant can be kept alive whilst awaiting recovery of food tolerance is 20 to 30 days, but he also points out that there are many diarrhoeas which last longer than this and that some method of supplementing calories must be found. This will be discussed later.

\section{Immediate Treatment}

Disturbances of chemical equilibrium occur on account of the vomiting, diarrhoea, and subsequent oliguria and dehydration. The vomiting gives rise to loss of hydrochloric acid and base chloride, and consequent alkalosis. The diarrhoea causes loss of base bicarbonate and as a result acidosis. Oliguria gives rise to an increase in the N.P.N. of the blood. When these physiological changes were first observed and it was felt that oral feeding was contra-indicated, saline was given parenterally as sodium chloride. As there was a marked tendency towards retention of base chloride leading to a resultant reduction of base bicarbonate and the development of acidosis, this was found to be contra-indicated. Because of this and because of the frequent loss of base bicarbonate from the body, sodium bicarbonate was substituted. It was found however, that there were several objections to the use of sodium bicarbonate. If given intravenously in amounts large enough to be effective it produced too rapid changes in the reaction of the body fluids with the result that there might be an immediate shift from an uncompensated acidosis to an uncompensated alkalosis. In addition there were difficulties in sterilizing the sodium bicarbonate before it was given parenterally. Hartmann and Senn ${ }^{37}$ then introduced sodium lactate and lactate Ringers solutions which by virtue of their buffer content are extremely effective in the isotonic form in relieving severe acidosis and in the form of the physiological buffer salt solution in relieving either mild acidosis or alkalosis. By the more gradual transformation they do not lead to the severe reactions obtained with bicarbonate. In spite of these advances, however, the ultimate results of treatment did not improve greatly and Darrow ${ }^{38}$ (1946) stated 'the comprehensive plan for the treatment of diarrhoea published by Powers ${ }^{39}$ in 1926 apparently produced as satisfactory results as any.' Darrow then claimed that diarrhoea led to a loss of intracellular potassium and that if during the period of fasting one could retain intracellular potassium by adding potassium chloride to the mixture containing sodium chloride, sodium lactate, and glucose one could supply the substance which by its lack was contributing to the continued high mortality rate in the disease. He did, however, point out that care had to be taken to avoid potassium intoxication but that if attention was paid to establishment of kidney function before administration there was little danger of this occurring. He quoted two series of cases in which three out of 50 children with the new treatment and 17 out of 53 with the old died. He did not, however, use alternate cases, although he stated that the cases were strictly comparable.

\section{Maintenance of Metabolic Requirements}

As mentioned earlier Gamble has pointed out that whilst providing water and electrolytes parenterally can sustain body fluids for a period there is also a considerable energy deficit which commences with the onset of the diarrhoea. Energy requirements can be provided by glucose, but more than a Io per cent. solution is irritant to the veins. Various people have tried to overcome this difficulty and provide the necessary energy requirements by using casein hydrolysates. These in their earlier forms were found to be irritant to the veins in concentrated form and Hartmann suggested that they be used subcutaneously with a $\mathrm{PH}$ of 6 and in a $3 \frac{1}{3}$ per cent. solution. There still appears to be a difference of opinion as to the advisability of their use intravenously, some claiming that any reactions produced are due to errors in technique. They have been found to be of value in the more chronic case, especially where there has been found to be evidence of liver damage. Care must be taken to ensure that the peripheral circulation is satisfactory before their use.

It does appear however, that even when aminoacids are given, the greater part of them is oxidized for energy requirements and more recently it has been suggested that what is still required in the long term case is an emulsion of fat suitable for parenteral injection. Shafiroff and Frank ${ }^{40}$ have 
prepared an emulsion of fat suitable for intravenous therapy and have given it for a period of over eight days without ill effects. Magee ${ }^{41}$ quotes Ivy as preparing a fat emulsion capable of keeping dogs in nitrogen balance and good health when given intravenously for over 42 days.

\section{Plasma and Whole Blood Transfusions}

In cases where there is evidence of severe initial shock with poor response to glucose saline solution or where the plasma proteins are markedly depleted, or there is anaemia, these may be found to be of value and also perhaps at a stage in the diarrhoea where there is little resistance and there is the possibility of secondary infection.

\section{Vitamins}

These may also play a part in the chronic case and in those cases where evidence of liver damage has been found vitamin $\mathrm{K}$ may be of particular value.

\section{Feeding}

There is considerable agreement that starvation should be continued until there is evidence that the diarrhoea has been controlled. This may take several days. Initial feeding should commence with the use of expressed breast milk, separated lacidac or protein milk, and the caloric intake should be small at first, taking a week to reach full caloric requirements. In the intermediate period before full requirements are reached fluid intake must be kept up parenterally. Once the breast milk or separated milk is being digested without upset, a gradual change-over should be made to a half cream milk and then, according to the age of the infant, a full cream one.

\section{Discussion}

The history of infantile diarrhoea and vomiting has been reviewed. The aetiology of the disease has been discussed and evidence produced to show that, in some instances at least, the disease may be caused by a virus. Stress is laid on the importance of ensuring that more stringent care is taken over the administration of nurseries for the newborn, particularly as the incidence of the disease in the first month of life is increasing along with an increasing tendency for babies to be born in hospital rather than at home, for various reasons including better obstetric care, shortage of home facilities and economic necessity.

It is pointed out that the morbidity and mortality from the disease is diminishing as a result of the recognition of the infectious nature of the disease, better isolation facilities, better. nursing technique and better medical treatment including the treatment and prevention of complications by the use of chemotherapy and antibiotics. Treatment is discussed in its various stages. Initial treatment is aimed at resting the alimentary tract, treatment of collapse and restoration of fluid loss, replacement of electrolytes and restoration of acid-base metabolism to normal. On how all this is carried out there is not, as yet, complete agreement. For instance some recommend restoration of kidney function by means of intravenous plasma, whilst others consider glucose saline equally effective. Then some consider that if kidney function is satisfactory and enough fluid is supplied in the form of glucose saline or plasma any acidosis or alkalosis present may be corrected without the use of bicarbonate or Hartmann's solution. On the whole, however, Hartmann's solution seems to be used naw by most people. Darrow's views on the necessity for increased potassium intake have been mentioned. Although his views have not yet met with general acceptance, in the writer's opinion, from limited personal use of his solution, it does appear to have special merit. Maintenance therapy may be carried out by the use of 10 per cent. glucose intravenously with, in the more chronic cases the addition of casein hydrolysates, remembering that the latter have the disadvantage of causing, in some cases at least, severe local reactions. The need in some cases for blood plasma to replace protein loss and whole blood to combat anaemia is mentioned as is the use of vitamins, particularly vitamin $\mathrm{K}$ in the more chronic cases. The suggestion made by recent writers that soluble fat is required in emulsion form, to supply sufficient food for body growth in addition to energy requirements, is mentioned and also the fact that such an emulsion has apparently been given intravenously with some success.

Diet is discussed and it is pointed out that the main essentials are delay in commencement of feeding until the diarrhoea has ceased, initial use of either breast milk or a milk with a low fat content such as separated lacidac; and a slow increase in feeding until full caloric requirements are reached, taking care that the full fluid requirements are maintained.

\section{REFERENGES}

I. GARRISON, F. H. (1929), ' History of Medicine,' 4th Edition Philadelphia.

2. CARTER, A. H. (1893), Prov. Med. F., 12, 236, 292, 349.

3. WILSON, G. S. (1927), F. Hygiene, 26, 170 .

4. MARRIOTT, W. McK. (1923), Phys. Rev., iii, 275.

MARRIOT', W. McK. (1925), Trans. Amer. Ped. Soc., 37, 38.

5. FINDLAY, L. (1932), Arch. Dis. Child., 7, 307.

6. CRAIG, W. S. (1936), Lancet, $2,85$.

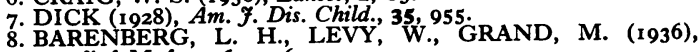

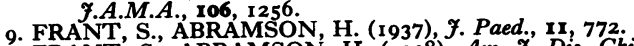

FRANT, S., ABRAMSON, H. (1938), Am. F. Dis. Child., 5,

FRANT, S., ABRAMSON, H. (1939), ' New York State Journal

10. WATT, J., CARLTÓN, E. (1945), 'Public Health Reports,'

WATT, J. (1945), Am. J. Public Health, 35, 1205. 
11. McKINLAY, B. (1937), Am. F. Dis. Child., 54, 1252.

12. SELIGMANN, E., BARASH, L., COHLAN, S. Q. (1947), 7. Paed., 30, 182 .

13. ENSIGN, P. R., HUNTER, C. A. (1946), F. Paed. 29, 620.

14. FELSEN, J., WOLANSKY, W. (I942), Arch. Paed, 59, 495

15. DRAPER, F., BROWN, G. W. (1946), M. F. Australia, I, 469.

16. ORMISTON, G. (1941), Lancet, 2, 588 .

17. PAYLING WRIGHT, G., PAÝLING WRIGHT, H. (1946), Hyg. F., 480 .

PAYLING.'WRIGHT, G., PAYLING WRIGHT, H. (1946), Hyg. F., 15.

PAYLIN. F." WRIGHT, G. (1948), Proc. Royal Soc. Med., 4I, 182.

18. NETER, E. R., CLARK, P. (1944), F. Digest. Dis., 356.

19. McCLURE, W. B. (1943), $\dot{y}$. Paed., 22, 60.

20. BAKER, C. J. (1939) Ұ. Paed., 14, 183.

21. JAMES, U. (1947), Arch. Dis. Child., 22 180.

22. COOPER, E. D. (1937), Arch. Dis. Child., 7, 307.

23. CAMLLIE, J. M. (I939), Lancet, 1, 969., 4 , A. (1941), Arch. Dis. Child., 16, 211 .
25. ALEXINDER, M. B., EISER, Y. (I944), B.M.F., $2,425$.

26. GAIRINER, P. (1945), Arch. Dis. Child., 20, 22.

27. PATTIERSON, W. H., SMITH, G. S. (1944), B.M.F., 2, 659. 28. WYLLIE, W. G. (1948), Proc. Royal Soc. Med., 41, 182. 29. LYON, G. M., FOLSOM, T. G. (1941), Am. F. Dis. Child., 을

30. LIGH'C, J. S., HODES, H. L. (1943), Am. F. Public Health $33,1451$.

3r. CUMNIINGS, G. D. (1947), F. Paed., 30, 706.

32. SEVITT, S. (1948), Proc. Roy. Soc. Med., 4I, 182.

33. BUDDINGH, G. J., DODD, K. (1944), f. Paed., 25, 105.

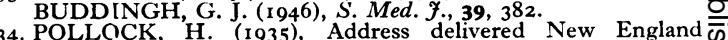
Hospital Association, Boston, March 9th

35. CLIFF(ORD, S. H. (I947), New England Med. F., 26, 969.

36. GAMBLE, J. L. (1947), Ұ. Paed., 30, 488 .

37. HARTMANN, A. F., SENN, M. J. E., 尹. Clin. Invest., 11, 337. עִ 38. DARROW, D. O. (1946), F. Paed., 28, $515,541,550$.

39. POWERS, G. F. (1926), A. F. Dis. Child., 32, 232 .

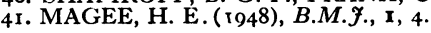

\section{LA Y CLINICIANS}

No. 12

Often when reading a book or play one comes across an excellent description of some disease. Such accounts are always of interest to the doctor and they often show surprisingly accurate powers of observation and clinical acumen. We hope to print some of these 'case records' from time to time and for those who would like to try their hand at naming the author, this information will be given at the end of the extract.

' Certainly the occupants of the landaulet were bizarre enough to attract attention even in the worldly Paris. But the figure perched on the driver's seat held the added fillip of surprise. Seated there, his legs braced against the high footboard, his knees covered with a driver's rug, his powerful arms and hands managing the two neat chestnuts with a true horseman's deftness of touch, there seemed nothing remarkable about the coachman, Cupidon. It was only when he threw aside the rug, clambered down over the wheel as agilely as a monkey and stood at the kerb that you saw with staring unbelief the man's real dimensions. The large head, the powerful arms and chest belonged to a dwarf, a little man not more than three feet high. His bandy legs were like tiny stumps to which the wee feet were attached. This gave him a curiously rolling gait like that of a diminutive drunken sailor on shore leave. The eyes in the young-old face were tender, almost wistful ; the mouth sardonic, the expression pugnacious or mischievous by turn. This was Cupidon, whom they fondly called Cupide ; bodyguard, coachman, major-domo. When he spoke, which was rarely, it was in a surprisingly sweet clear tenor like a choirboy whose voice had just changed. He might have been any age-fifteen, twenty, thirty, forty. There were those who said that, though white, he was ${ }^{\infty}$ Kakaracou's son. Certainly she bullied him and pampered him by turns. Sometimes you saw her ${ }_{c}^{\vec{C}}$ withered hand resting tenderly on the tiny man's head; sometimes she cuffed him smartly as though he were a naughty child. She managed कof save the choicest titbits for his plate after te ${ }^{\infty}$ others had finished, she filled his glass with god्ठ잉 red wine of the country as they sat at the servan table, he in his specially built high chair on whicho he clambered so nimbly up and down.

“ Drink your red wine, Little One. It will make $\frac{\stackrel{\mathbb{D}}{\Omega}}{2}$ you strong."

'Instead of thumping his chest or flexing his arm윽 he would rap his head briskly. " I don't need red? wine to make me strong. I'm strong enough.0. Here's my weapon." But he would toss down the glassful, nevertheless, giving the effect as he did 3 . so of a wickedly precocious little boy in his cups. Everyone in the household knew that his boast. was no idle one. That head, hard and thick as ao cannonball, was almost as effective when directed against an enemy. Thigh-high to a normallyo built man, he would run off a few steps, then $>$ charge like a missile, his head thrust forward and? down, goat fashion. On a frontal attack, meñ twice his size had been known to go down with one grunt, like felled oxen.'

This colourful description of an achondroplasie dwarf appears in a recent novel, 'Saratoga Trunk 6 by Edna Ferber. Dwarfs of all descriptions are encountered in the world's literature but frequently ${ }^{\text {? }}$ they are the product of the author's imagination Edna Ferber, however, gives us a pen picture of the्ष condition which was first described by voß Soemmerring in 1791 . 